\title{
Inflation, its Volatility and the Inflation-Growth Tradeoff in India ${ }^{1}$
}

\author{
Raghbendra Jha \\ Australian National University
}

and

Varsha S. Kulkarni

Indiana University Bloomington

USA

\begin{abstract}
This paper amends the New Keynesian Phillips curve model to include inflation volatility. It provides results on the determinants of inflation volatility and expected inflation volatility for OLS and ARDL $(1,1)$ models and for change in inflation volatility and change in expected inflation volatility using ECM models. Output gap affects change in expected inflation volatility alone (in the ECM model) and not in the other models. Major determinants of inflation volatility and expected inflation volatility are identified. To the best of our knowledge this is the first paper to augment the New Keynesian Phillips Curve to include inflation volatility.
\end{abstract}

Keywords: Inflation, Inflation volatility, ARDL model, ECM model, Output gap, India

JEL classification: E31, E32, E42, E44

Please address all correspondence to:

Prof. Raghbendra Jha, ASARC, Arndt-Corden Dept of Economics, H.C. Coombs Building (09)

Australian National University, Canberra, ACT 0200, Australia

Phone: + 6126125 2683, Fax: + 6126125 0443, Email: r.jha@anu.edu.au

\footnotetext{
${ }^{1}$ Thoughts and views sought from Raghav Gaiha and Eric Smith were helpful for this paper. We are grateful to a summer scholarship granted to Varsha S. Kulkarni by the Santa Fe Institute, where some of this work was completed.
} 


\section{INTRODUCTION}

Recent literature, ${ }^{2}$ for several countries over time, suggests that the volatility of inflation is an important determinant of the tradeoff between inflation and economic growth. It is established as one of the important factors affecting the overall volatility for some countries and in fact a reduction in inflation volatility has accompanied a reduction in output gap volatility. This paper explores this issue further in the context of a particular country, India.

Recent analysis has indicated the importance of inflation volatility for the monetary transmission mechanism in India (Kapur and Behera, 2012). In the analysis of such monetary policy mechanisms the New Keynesian Phillips Curve (henceforth NKPC) has proved to be a useful tool. Thus Patra and Ray (2010) for India and Brissimis and Magginas (2008) for the US find considerable support for the standard NKPC.

The purpose of this paper is to extend the standard NKPC framework to include inflation volatility and test its significance for the case of India. The paper is organized as follows. Sections II and III describe the NKPC and the mathematical formulation of the incorporation of inflation volatility therein, respectively. We discuss the data and methods of analysis in section IV which is followed by results in section V. Finally, section VI concludes. To the best of our knowledge this is the first paper to extend the NKPC framework to include inflation volatility.

\section{THE NEW KEYNESIAN PHILLIPS CURVE}

The NKPC combines the properties of rational expectations and sticky prices. The sticky price stipulation follows the work of Calvo (1983). A random fraction (1- $\theta$ ) of firms is able to reset their prices whereas the fraction $\theta$ keep their prices unchanged. When firms change prices they take into account the fact that the prices may remain fixed for several periods. In line with the literature it is assumed that firms choose a $\log$ price, $\mathrm{z}_{\mathrm{t}}$, to minimize the following loss function:

$L\left(z_{t}\right)=\sum_{k=0}^{\infty}(\theta \beta)^{k} E_{t}\left(z_{t}-p^{*}{ }_{t+k}\right)^{2}$

Here $1>\beta>0$ is the discount factor and $\mathrm{p}^{*}{ }_{\mathrm{t}+\mathrm{k}}$ is the optimal price that the firm would set in period $\mathrm{t}+\mathrm{k}$ in the absence of any price rigidity. The term within the expectations operator denotes the square of the undiscounted loss. Future losses are discounted at the rate $(\theta \beta)^{k}$ and the summation over all possible $\mathrm{k}$ future periods shows the effect current price on all future periods. If $\beta<1$ then the firm would place more weight on current losses as compared to those incurred in future. Calvo (1983) derives the optimal price to be set by the firm to be:

\footnotetext{
${ }^{2}$ For a review of this literature in a cross country context see Jha and Dang (2012).
} 


$$
z_{t}=(1-\theta \beta) \sum_{k=0}^{\infty}(\theta \beta)^{k} E_{t}\left(\mu+m c_{t+k}\right)
$$

The optimal fully flexible price in period $\mathrm{t}+\mathrm{k}$ is a mark-up $(\mu)$ over marginal cost $(\mathrm{mc})$.

This implies that the optimal loss-minimizing solution is for the firm to set its price equal to a weighted average of the optimal fully flexible prices over time. These weights are declining over time.

The aggregate price level in this economy is a weighted average of last period's aggregate price level and the new reset price with the weight being determined by $\theta$. Thus:

$$
p_{t}=\theta p_{t-1}+(1-\theta) z_{t}
$$

This can be re-arranged to express $\mathrm{z}_{\mathrm{t}}$ as:

$$
z_{t}=\frac{1}{1-\theta}\left(p_{t}-\theta p_{t-1}\right)
$$

Now, (2) is a first order difference equation with the solution given as

$$
z_{t}=\theta \beta E_{t} z_{t+1}+(1-\theta \beta)\left(\mu+m c_{t}\right)
$$

Substituting the result in (5) into (4) we get (assuming $E_{t} p_{t} \sim p_{t}$ ):

$$
\begin{aligned}
& \frac{1}{1-\theta}\left(p_{t}-\theta p_{t-1}\right)=\frac{\theta \beta}{1-\theta}\left(E_{t} p_{t+1}-\theta p_{t}\right)+(1-\theta \beta)\left(\mu+m c_{t}\right) \\
& \pi_{t}=\beta E_{t} \pi_{t+1}+\frac{(1-\theta)(1-\theta \beta)}{\theta}\left(\mu+m c_{t}-p_{t}\right)
\end{aligned}
$$

where $\pi_{t}=p_{t}-p_{t-1}$ is the rate of inflation. Thus, inflation depends positively on real marginal cost $\left(m c_{t}-p_{t}\right)$. Hence, if the ratio of marginal cost to price is high firms will raise prices when resetting these.

This expression is often labeled the NKPC. Clearly this equation incorporates the effect of forward expectations $E_{t} p_{t+1}$. Duffy and Xiao (2011) show that the neoclassical augmented Phillips Curve differs from NKPC in just this term.

\section{VOLATILITY OF INFLATION}

We now use the standard Phillips curve:

$$
\pi_{t}=\pi_{t-1}+\alpha-\beta u_{t}
$$

where $u_{t}$ is the unemployment rate . (8) is interpreted as a relation between change in inflation and unemployment level. 
Next we integrate (7) and (8) and introduce into the resultant relationship the notion of inflation volatility. Three alternative notions of inflation volatility could be used:

(a) $\Delta \pi=\pi_{t}-\pi_{t-1}$

(b) $\Delta \pi=\left|\pi_{t}-\pi_{t-1}\right|$, or

(c) $\Delta \pi=\sum_{t}\left|\pi_{t}-\pi_{t-1}\right|$

We take the simplest case (a) here. So $\pi_{t}=\Delta \pi+\pi_{t-1}$

Substituting (9) on the LHS of equation (8) and using (7), we get:

$$
\begin{aligned}
\Delta \pi & =-\pi_{t-1}+\beta E_{t} \pi_{t+1}+\frac{(1-\theta)(1-\theta \beta)\left(\mu+m c_{t}-p_{t}\right)}{\theta} \\
& =\alpha-\beta u
\end{aligned}
$$

Now if $u=u^{*}$, the non-accelerating inflation rate of unemployment (henceforth NAIRU), $\Delta \pi=0$, so we can get a relationship between $\pi_{t-1}, E_{t} \pi_{t+1}$ and $p_{t}$ but

$p_{t}=p_{t-1}+\pi_{t}$, so we have a relation between inflation at current time, backward time, forward time.

If $u \neq \mathrm{NAIRU}$, then it can be shown that $p_{t}=\mu+m c_{t}-\frac{\theta \pi_{t-1}+\theta \Delta \pi-\beta \theta E_{t} \pi_{t+1}}{(1-\theta)(1-\theta \beta)}$

(11) incorporates inflation variability.

If $\mu+m c_{t}-p_{t}=\lambda y_{t}$ then

$\Delta \pi=-\pi_{t-1}+\beta E_{t} \pi_{t+1}+\gamma y_{t}$

with $\gamma=\frac{(1-\theta)(1-\theta \beta)}{\theta} \lambda$

If we rework the NKPC using $\Delta \pi$ we get:

$$
z_{t}=\frac{(1-\theta) p_{t-1}+\pi_{t}}{1-\theta}
$$

as the modified form of (4).

Unanticipated inflation is $\left(\pi_{t}-E_{t} \pi_{t}\right)$ which would then be used to scale the term $E_{t} \pi_{t+1}-E_{t} \pi_{t}$.

We also know from (5) $z_{t}=\theta \beta E_{t} z_{t+1}+(1-\theta \beta)\left(\mu+m c_{t}\right)$, so from (13) above we get

$\theta \beta E_{t} p_{t}+\frac{\theta \beta}{(1-\theta)} E_{t} \pi_{t+1}+(1-\theta \beta)\left(\mu+m c_{t}\right)=p_{t-1}+\frac{\pi_{t}}{(1-\theta)}$

Now considering $\pi_{t+1}=\pi_{t}+\Delta \pi_{t+1}$, we get 


$$
E_{t}\left(\Delta \pi_{t+1}\right)=\frac{\pi_{t}}{\theta \beta}-E_{t} \pi_{t}-(1-\theta) E_{t} p_{t}-(1-\theta) \frac{(1-\theta \beta)}{\theta \beta}\left(\mu+m c_{t}\right)+\frac{(1-\theta)}{\theta \beta} p_{t-1}
$$

From the definition of inflation, $p_{t-1}=p_{t}-\pi_{t}$

$$
E_{t}\left(\Delta \pi_{t+1}\right)=\frac{\pi_{t}}{\beta}-E_{t} \pi_{t}-(1-\theta) E_{t} p_{t}-(1-\theta) \frac{(1-\theta \beta)}{\theta \beta}\left(\mu+m c_{t}\right)+\frac{(1-\theta)}{\theta \beta} p_{t}
$$

If $\mu+m c_{t}-p_{t}=\lambda y_{t}$

$$
E_{t}\left(\Delta \pi_{t+1}\right)=\frac{\pi_{t}}{\theta \beta}-E_{t} \pi_{t}-(1-\theta) E_{t} p_{t}+(1-\theta) p_{t}-\gamma^{\prime} y_{t}
$$

Where $\gamma^{\prime}=\frac{(1-\theta)(1-\theta \beta)}{\theta \beta} \lambda$

Eq. (15) gives the relation between expected future inflation volatility and the difference between (scaled) actual inflation at previous time and the expected inflation at that time.

\section{DATA \& METHODS}

We use the yearly Consumer Price Index (henceforth CPI) and Gross Domestic Product (henceforth GDP) per capita for India obtained from the International Monetary Fund (henceforth IMF) database for the period of 1960-2008. We use the following methods to estimate equations (12) and (15) derived above.

\section{A. Computing Expected Values}

The output gap $y$ is defined as the difference between actual GDP per capita and the predicted or expected GDP per capita. We compute the expected values of GDP per capita using the model

$$
E_{t} G D P_{t}=a_{1} b_{1}^{t}
$$

with an aim of fitting the typical trend of growth rate (Dornbusch, Fischer, Startz 2000). Here $a_{1}$ represents the initial GDP level and $b_{1}$ represents the growth rate. Similarly we obtain the expected values of price (CPI), inflation ( $\pi$ ) and volatility of inflation (as defined in (a) above) from equations $16 \mathrm{~b}, \mathrm{c}, \mathrm{d}$ respectively as follows

$$
\begin{aligned}
& E_{t} p_{t}=a_{2} b_{2}{ }^{t} \\
& E_{t} \pi_{t}=a_{3} b_{3}{ }^{t} \\
& E_{t}\left(\Delta \pi_{t}\right)=a_{4} b_{4}{ }^{t}
\end{aligned}
$$

Again, the $a$ 's and $b$ 's represent the initial level of the variable whose expected value is calculated and growth rates respectively. Apart from these models the expected values of these variables may also be 
computed using (linear) model: $Y_{t}=\alpha+\beta t$ or (quadratic) model: $Y_{t}=a+b t+c t^{2}$, a decision we make based on statistical concerns outlined below.

\section{B. Testing for co-integration}

The Ordinary Least Squares (OLS henceforth) regressions applied above in equations (12), (15) and (16) may be rendered spurious due to the non-stationarity of the time series employed. Two nonstationary time series are co-integrated if they move together over time. We apply the method introduced by Engle and Granger (1987) to test for co-integration between the non-stationary time series. The test involves performing an Augmented Dickey-Fuller test on the residual $u$ of the regression models to determine if it is stationary as

$\Delta u_{t} \sim u_{t-1}$

The test rejects or accepts the null hypothesis of no co-integration or non-stationarity based on the value of $t$ statistic obtained in (17). If the residual is stationary $(\mathrm{I}(0))$, the time series are co-integrated. The time series that are not co-integrated or stationary are corrected using different transformations such as differencing and other methods. If these transformations fail to induce co-integration for Eqs (16), the output gap may alternatively be determined using linear or quadratic models stated in the previous sub-section.

\section{Autoregressive Distributed Lags}

In carrying out the OLS regressions for the time series models above, smaller sample sizes may be a cause of concern as the errors or disturbances may be serially correlated. We adopt the method of Autoregressive Distributed Lags (henceforth ARDL) to deal with this issue here. An ARDL model treats the autocorrelation dynamics as part of the model thereby including the lagged dependent variable as well as the lagged independent variable. In general an autoregressive model with finite distributed lags is called ARDL $(p, q)$ which has $p$ lags of dependent variable and $q$ lags of independent variable. The model implies the absence of error autocorrelation and the number of lags required so as to yield consistent variance estimators. We estimate the ARDL $(1,1)$ model of equations (12) and (15) which already consist of forward and backward lagged variables. We consider original uncorrected data as before, the results show that the variables are fairly more significant in case of (12) as compared to (15).

\section{Error Correction Mechanism}

There may be delays or lags involved in the relationships established in eqs (12), (15) due to which it may take the system longer time to adjust. In order to detect the presence of a long term relationship between the variables on left and right hand side we employ the Error Correction Mechanism (henceforth ECM). ECM can be applied to any model that estimates the rate at which changes in dependent variable come back to equilibrium when there is a change in the independent variable. In 
this model $Y_{t}^{*}$ is the desired level of dependent variable $Y$ that would correspond to the level of independent variable $X$ in the long run

$Y_{t}^{*}=\gamma_{1}+\gamma_{2} X_{t}+u_{t}$

In the short run the change in $Y$ depends on the discrepancy between appropriate and observed values at the previous time and the change in independent variable.

$$
\Delta Y_{t}=\lambda\left(Y_{t}^{*}-Y_{t}\right)+\delta \Delta X_{t}+u_{t}
$$

Thus ECM justifies the long run relation between dependent and independent variables and the short run changes in dependent variables in response to long run equilibrium. This is applied in the general model as

$Y_{t}=\lambda \gamma_{1}+\delta X_{t}+\left(\lambda \gamma_{2}-\delta\right) X_{t-1}-\lambda Y_{t-1}+u_{t}$

Here $\delta$ represents the short run effect of $\mathrm{X}$ on $\mathrm{Y}$ and $\lambda$ is the rate at which the model re-equilibrates. We apply this method to our equations (12), (15).

\section{RESULTS}

Time series plots of the key variables used in the analysis for the period 1960-2008 are reported in Figures 1 to 4 . Figure 1 plots $\log$ CPI, figure 2, log of output gap, figure 3 inflation and figure 4 plots inflation volatility. There does not appear to be a break in any of the time series.

\section{Figures 1 to 4 here}

Our estimation of the two equations (12), (15) for India reveals that the problem of non-stationarity or absence of co-integration does not occur for any of the variables. However, in the estimation of the expected inflation volatility with eq. 16(d), the series are integrated of order 1 (i.e., I(1)). We employ differencing to make them stationary or $\mathrm{I}(0)$.

Table 1 presents results on OLS estimation of inflation volatility for the period 1960 to 2008. Output gap $y$ has a small negative but insignificant effect; Inflation_has a strong negative significant effect and expected inflation has strong positive significant effect on inflation volatility.

\section{Table 1 here.}

Table 2 presents results on OLS estimation of expected inflation volatility using Eq. 15. We find that the output gap drops out; the level of inflation has a positive and highly significant effect; price has a small, positive and fairly significant effect; expected price has a small positive and insignificant effect. 


\section{Table 2 here.}

Table 3 reports results on ARDL $(1,1)$ estimation of Inflation volatility. Our principal results are as follows: Output gap and lagged output gap have small negative and insignificant effects; Inflation has a strong negative and significant effect; lagged inflation drops out; expected inflation has a strong positive and significant effect and lagged expected inflation drops out. Lagged inflation volatility has a negative but insignificant effect.

\section{Table 3 here.}

In Table 4 we report on estimation of $\operatorname{ARDL}(1,1)$ model for analyzing expected inflation volatility. Lagged output gap has negative significant effect; lagged inflation has a very small and insignificant effect; price has a positive and highly significant effect; expected price has a negative significant effect. Output gap, price, lagged price and lagged expected price drop out.

\section{Table 4 here.}

Finally, we report results on ECM estimation of changes in inflation volatility and expected inflation volatility in Tables 5 and 6 respectively. In Table 5 the dependent variable is Change in Inflation volatility. Change in output gap between two successive times has a small positive and non significant effect; change in inflation drops out; change in expected inflation has a strong negative and highly significant effect; lagged inflation volatility has a negative and highly significant effect; lagged output gap has a small negative but insignificant effect; lagged inflation has a negative and highly significant effect; lagged expected inflation has a positive and significant effect.

\section{Tables 5 and 6 here}

Table 6 models change in expected inflation volatility. None of the variables is significant here. Change in inflation between two successive times, change in output gap, lagged output gap and lagged expected price have almost no effect; change in expected inflation has a positive insignificant effect; lagged expected inflation volatility and lagged expected inflation have a small negative but insignificant effect; change in expected price, change in price, lagged inflation and lagged price drop out. Hence, as per the ECM estimation expected inflation volatility appears to be a random process, although this is not the case with the OLS or the ARDL estimations.

\section{DISCUSSION \& CONCLUSIONS}

In this paper we present results on the determinants of inflation and expected inflation volatility in the Indian context. To the best of our knowledge this is the first paper to extend the NKPC framework to include inflation volatility. 
We employ methods of OLS and ARDL $(1,1)$ for the estimation of inflation and expected inflation volatility as well as changes in these variables through ECM estimation. OLS estimation reveals that actual inflation volatility rises with expected inflation and falls when the level of inflation goes up, although the output gap has no significant impact. However, in the case of expected inflation volatility the level of inflation has a strong positive and significant impact whereas price has a positive but only weakly significant impact. Expected price is insignificant.

Since some of the variables used are non-stationary we also reported on ARDL estimation of the determinants of inflation volatility and expected inflation volatility. In the case of inflation volatility output gap, lagged output gap and lagged inflation volatility are all insignificant. The level of inflation has a negative significant impact whereas the level of expected inflation has a positive and significant impact. In the case of expected inflation volatility lagged output gap has a negative and significant impact, the price level has a positive and significant impact whereas expected price has a negative and weakly significant impact. Lagged inflation is insignificant.

ECM estimation reveals change in inflation variability falls significantly with lagged inflation volatility and lagged inflation and less significantly with change in expected inflation. It rises with lagged expected inflation although the coefficient is only weakly significant. Lagged output gap and change in output gap are insignificant. The ECM for analyzing change in expected inflation volatility appears to be quite random with no significant variables.

There is evidence that for some other countries with financial liberalization there is a reduction in inflation volatility and output volatility which is consistent with theoretical research that liberalization allows risk-sharing, financial markets better manage traders' consumption decisions, and better monetary policies bring down output volatility, which in turn may affect inflation volatility. Thus our results in the Indian context corroborate the relevance of these considerations in the analysis of inflation volatility. 


\section{REFERENCES}

Brissimis, S. and N. Magginas (2008), 'Inflation Forecasts and the New Keynesian Phillips Curve', International Journal of Central Banking, 4(2), 1-22.

Calvo, G. (1983), 'Staggered Prices in a Utility-Maximizing Framework', Journal of Monetary Economics, $12(3), 383-98$.

Dornbusch, R., Fischer, S. and Startz, R (2000) Macroeconomics, $7^{\text {th }}$ edn, Tata McGraw-Hill, New York and Delhi.

Duffy, J. and W. Xiao (2011), 'Investment and Monetary Policy: Learning and Determinacy of Equilibrium', Journal of Money, Credit and Banking, 43(5), 959-92.

Engle, R. and Granger, C (1987), 'Co-integration and error correction representation: Estimation and Testing', Econometrica, 55, 251-76.

Hassler, U. and Wolers, J (2006), 'Autoregressive distributed lags and co-integration', in Statistical Analysis, Springer, 90(1), 59-74.

Jha, R. and T. Dang (2012), 'Inflation Variability and the Relationship between Inflation and Growth', Macroeconomics and Finance in Emerging Market Economies, 5(1), 5-12.

Kapur, M. and H. Behera (2012), 'Monetary Transmission Mechanism in India: A Quarterly Model', WPS (DEPR): 09/2012, Department of Economic and Policy Research, Mumbai: Reserve Bank of India.

Patra, D. and P. Ray (2010), 'Inflation Expectations and Monetary Policy in India: An Empirical Exploration', WP/10/84, Washington DC: The International Monetary Fund. 
Table 1: Estimation of Inflation Volatility (Equation 12) for India (Dependent variable inflation volatility)

\begin{tabular}{|c|c|c|c|c|c|c|}
\hline \multicolumn{2}{|c|}{ Independent Variable } & \multicolumn{2}{|c|}{ Variable Description } & Coefficient & t-value & $\mathrm{P}>|t|$ \\
\hline \multicolumn{2}{|l|}{ Y } & \multicolumn{2}{|c|}{ Output Gap } & $\begin{array}{l}-0.0391 \\
(0.04)\end{array}$ & -0.89 & 0.378 \\
\hline \multicolumn{2}{|l|}{$\Pi$} & \multicolumn{2}{|c|}{ Level of Inflation } & $\begin{array}{l}-0.607 \\
(0.16)\end{array}$ & $-3.8^{\star * *}$ & 0.000 \\
\hline \multicolumn{2}{|l|}{$\pi^{e}$} & \multicolumn{2}{|c|}{ Expected Inflation } & $\begin{array}{c}0.594 \\
(0.17)\end{array}$ & $3.54^{\star \star \star}$ & 0.001 \\
\hline \multicolumn{2}{|l|}{ _cons } & \multicolumn{2}{|c|}{ Constant } & -0.033 & -0.11 & 0.912 \\
\hline \multicolumn{7}{|c|}{$\begin{array}{l}\text { Notes: Data source: CPI and GDP from IMF database for } 1960-2008 \text {. } \\
\text { Number of observations: } 46, F(3,42)=7.20 \text {, Prob }>F=0.0005, \\
\text { R-squared }=0.3397 \text {, Adjusted R-squared }=0.2925 \text {, Root MSE }=1.1434\end{array}$} \\
\hline Source & \multicolumn{2}{|l|}{ SS } & $\mathrm{df}$ & MS & & \\
\hline Model & \multicolumn{2}{|c|}{28.243} & 3 & 9.414 & & \\
\hline Residual & \multicolumn{2}{|c|}{54.909} & 42 & 1.307 & & \\
\hline Total & \multicolumn{2}{|c|}{83.153} & 45 & 1.847 & & \\
\hline
\end{tabular}

Note Source: CPI, GDP from IMF database; p-values * $0.1^{* *} 0.01^{* * *} 0.001^{* * * *}<0.001$; standard error in parentheses

Table 2: Estimation of Expected inflation volatility (Eq. 15) for India

\begin{tabular}{|l|l|c|c|c|}
\hline Independent Variable & Variable Description & Coefficient & t-value & $P>|t|$ \\
\hline$\Pi$ & Level of Inflation & $\begin{array}{c}0.0184 \\
(0.008)\end{array}$ & $2.26^{* * *}$ & 0.029 \\
\hline$P$ & Price & $\begin{array}{c}0.0038 \\
(0.0025)\end{array}$ & $1.47^{\star}$ & 0.147 \\
\hline EP & Expected price & $\begin{array}{c}0.0003 \\
(0.0025)\end{array}$ & 0.18 & 0.91 \\
\hline cons & Constant & $\begin{array}{c}0.023 \\
(0.013)\end{array}$ & $1.71^{\text {** }}$ & 0.09 \\
\hline
\end{tabular}

Notes: Data source: CPI and GDP from IMF database for 1960-2008. Standard error in parenthesis.

Number of observations: $46, F(3,42)=106.41$, Prob $>F=0.000$, R-squared $=0.8837$,

Adjusted R-Squared $=0.8754$, Root MSE $=0.0602$

\begin{tabular}{|l|l|l|l|}
\hline Source & SS & df & MS \\
\hline Model & 1.1574 & 3 & 0.38 \\
\hline Residual & 0.1522 & 42 & 0.0036 \\
\hline Total & 1.31 & 45 & 0.029 \\
\hline
\end{tabular}

Note Source: CPI, GDP from IMF database; p-values * $0.15^{\star *} 0.1{ }^{* * *} 0.003^{* * *}<0.003$; standard error in parentheses 
Table 3: Results of ARDL $(1,1)$ model for analyzing inflation volatility (Eq.12) for India

\begin{tabular}{|l|l|c|c|c|}
\hline Variable Name & Variable Description & Coefficient & t-score & \multicolumn{1}{|c|}{$|t|$} \\
\hline$Y$ & Output Gap & $\begin{array}{l}-0.00932 \\
(0.1967)\end{array}$ & -0.05 & 0.962 \\
\hline Ly & Lagged output gap & $\begin{array}{l}-0.058 \\
(0.2229)\end{array}$ & -0.26 & 0.795 \\
\hline$\Pi$ & Inflation & $\begin{array}{l}-0.52 \\
(0.27)\end{array}$ & $-1.90^{* *}$ & 0.064 \\
\hline$\Pi^{e}$ & Expected inflation & $\begin{array}{c}0.554 \\
(0.308)\end{array}$ & $1.80^{* *}$ & 0.079 \\
\hline Led $\pi^{\mathrm{e}}$ & Lagged inflation volatility & $\begin{array}{l}-0.1551 \\
(0.191)\end{array}$ & -0.81 & 0.423 \\
\hline cons & Const & $\begin{array}{l}-0.0758 \\
(0.349)\end{array}$ & -0.22 & 0.830 \\
\hline
\end{tabular}

Number of observations: 45, F(5,39) $=4.24$, Prob $>F=0.0036$, R-squared=0.3523, Adjusted R-squared= 0.2693, Root MSE $=1.175$.

\begin{tabular}{|l|l|l|l|}
\hline Source & SS & Df & MS \\
\hline Model & 29.286 & 5 & 5.857 \\
\hline Residual & 53.84 & 39 & 1.38 \\
\hline Total & 83.13 & 44 & 1.889 \\
\hline
\end{tabular}

Note Source: CPI, GDP from IMF database; p-values ${ }^{*}<0.1^{* *} 0.05^{* * *} 0.001^{* * * *}<0.001$; standard error in parentheses

Table 4: Results of ARDL $(1,1)$ model for analyzing expected inflation variability (Eq.15) for India

\begin{tabular}{|c|c|c|c|c|c|}
\hline Variable Name & \multicolumn{2}{|c|}{ Variable Description } & Coefficient & t-score & $\mathrm{P}>\mid t$ \\
\hline Ly & \multicolumn{2}{|c|}{ Lagged output gap } & $\begin{array}{l}-0.015 \\
(0.0077)\end{array}$ & $-1.94^{* *}$ & 0.06 \\
\hline $\mathrm{L} \pi$ & \multicolumn{2}{|c|}{ Lagged inflation } & $\begin{array}{c}0.0002 \\
(0.012)\end{array}$ & 0.02 & 0.986 \\
\hline$P$ & \multicolumn{2}{|l|}{ Price } & $\begin{array}{l}0.016 \\
(0.007)\end{array}$ & $2.21^{* * *}$ & 0.033 \\
\hline eP & \multicolumn{2}{|c|}{ Expected Price } & $\begin{array}{l}-0.011 \\
(0.0068)\end{array}$ & $-1.63^{*}$ & 0.112 \\
\hline _cons & \multicolumn{2}{|c|}{ Constant } & $\begin{array}{l}0.025 \\
(0.013)\end{array}$ & $1.84^{\star \star}$ & 0.073 \\
\hline \multicolumn{6}{|c|}{$\begin{array}{l}\text { Number of observations: } 45, F(4,40)=86.47, \text { Prob }>F=0.000, \text { R-squared }=0.8963 \text {, Adjusted R-squared }=0.8863 \text {, Root MSE } \\
=0.05637 \text {. }\end{array}$} \\
\hline Source & SS & $\mathrm{df}$ & MS & & \\
\hline Model & 1.0994 & 4 & 0.2747 & & \\
\hline Residual & 0.127 & 40 & 0.003 & & \\
\hline Total & 1.226 & 44 & 0.0278 & & \\
\hline
\end{tabular}

Note Source: CPI, GDP from IMF database; p-values * $0.11^{* \star} 0.07^{* \star *} 0.03^{* * \star *}<0.001$; standard error in parentheses 
Table 5: Results of ECM for analyzing change in inflation volatility (Eq.12) for India

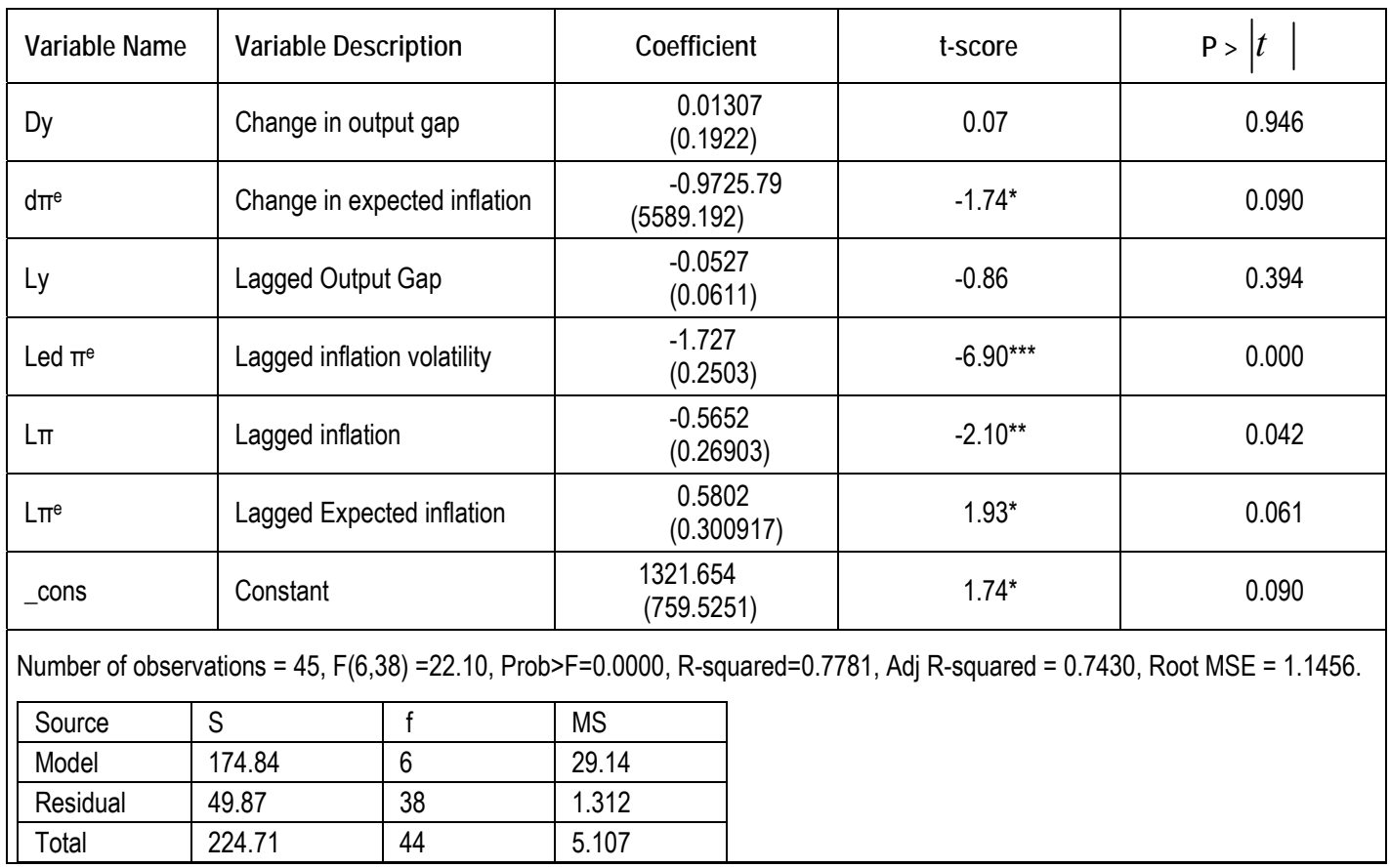

Note Source: CPI, GDP from IMF database; p-values * $<0.1^{* \star} 0.04^{* \star *} 0.001^{* * * *}<0.001$; standard error in parentheses

Table 6: Results of ECM for analyzing change in expected inflation volatility (Eq.15) for India

\begin{tabular}{|c|c|c|c|c|c|}
\hline Variable Name & \multicolumn{2}{|c|}{ Variable Description } & Coefficient & t-score & $\mathrm{P}>\mid t$ \\
\hline Dा & \multicolumn{2}{|c|}{ Change in inflation } & $\begin{array}{l}-0.0000009 \\
(0.000005)\end{array}$ & -0.2 & 0.84 \\
\hline $\mathrm{D} \pi^{\mathrm{e}}$ & \multicolumn{2}{|c|}{ Change in expected inflation } & $\begin{array}{l}0.088 \\
(0.11)\end{array}$ & 0.82 & 0.419 \\
\hline Dy & \multicolumn{2}{|c|}{ Change in output gap } & $\begin{array}{l}0.0000005 \\
(0.000006)\end{array}$ & 0.09 & 0.93 \\
\hline$L d \pi^{e}$ & \multicolumn{2}{|c|}{$\begin{array}{l}\text { Lagged expected inflation } \\
\text { volatility }\end{array}$} & $\begin{array}{l}-0.001 \\
(0.004)\end{array}$ & -0.31 & 0.755 \\
\hline$L \pi^{e}$ & \multicolumn{2}{|c|}{ Lagged expected inflation } & $\begin{array}{l}-0.002 \\
(0.008)\end{array}$ & -0.24 & 0.811 \\
\hline LeP & \multicolumn{2}{|c|}{ Lagged Expected price } & $\begin{array}{r}0.0000001 \\
(0.000002)\end{array}$ & 0.43 & 0.67 \\
\hline Ly & \multicolumn{2}{|c|}{ Lagged output gap } & $\begin{array}{l}-0.0000001 \\
(0.000002)\end{array}$ & -0.52 & 0.608 \\
\hline _cons & \multicolumn{2}{|l|}{ Constant } & $\begin{array}{l}0.016 \\
(0.01)\end{array}$ & 1.52 & 0.136 \\
\hline \multicolumn{6}{|c|}{ Number of observations $=45, F(7,37)=0.37$, Prob $>F=0.9135, R$-squared $=0.065$, Adj R-squared $=-0.11$, Root MSE $=0.000034$. } \\
\hline Source & SS & df & MS & & \\
\hline Model & 0.000000002 & 7 & 0.0000000004 & & \\
\hline Residual & 0.00000004 & 37 & 0.000000001 & & \\
\hline Total & 0.00000004 & 44 & 0.000000001 & & \\
\hline
\end{tabular}

Note Source: CPI, GDP from IMF database; p-values * $0.16^{* *} 0.01{ }^{* * *} 0.003^{* * *}<0.001$; standard error in parentheses 


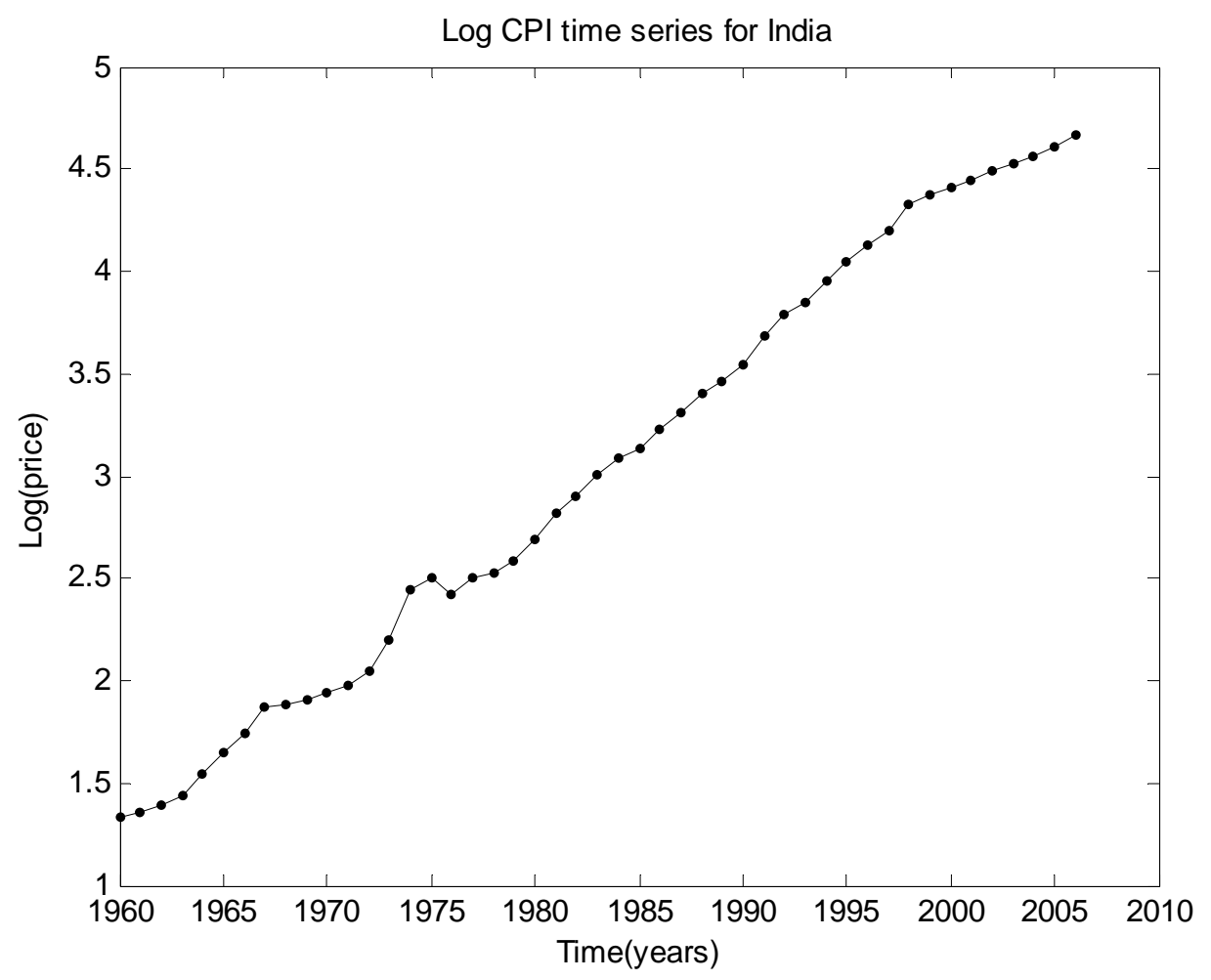

Figure 1

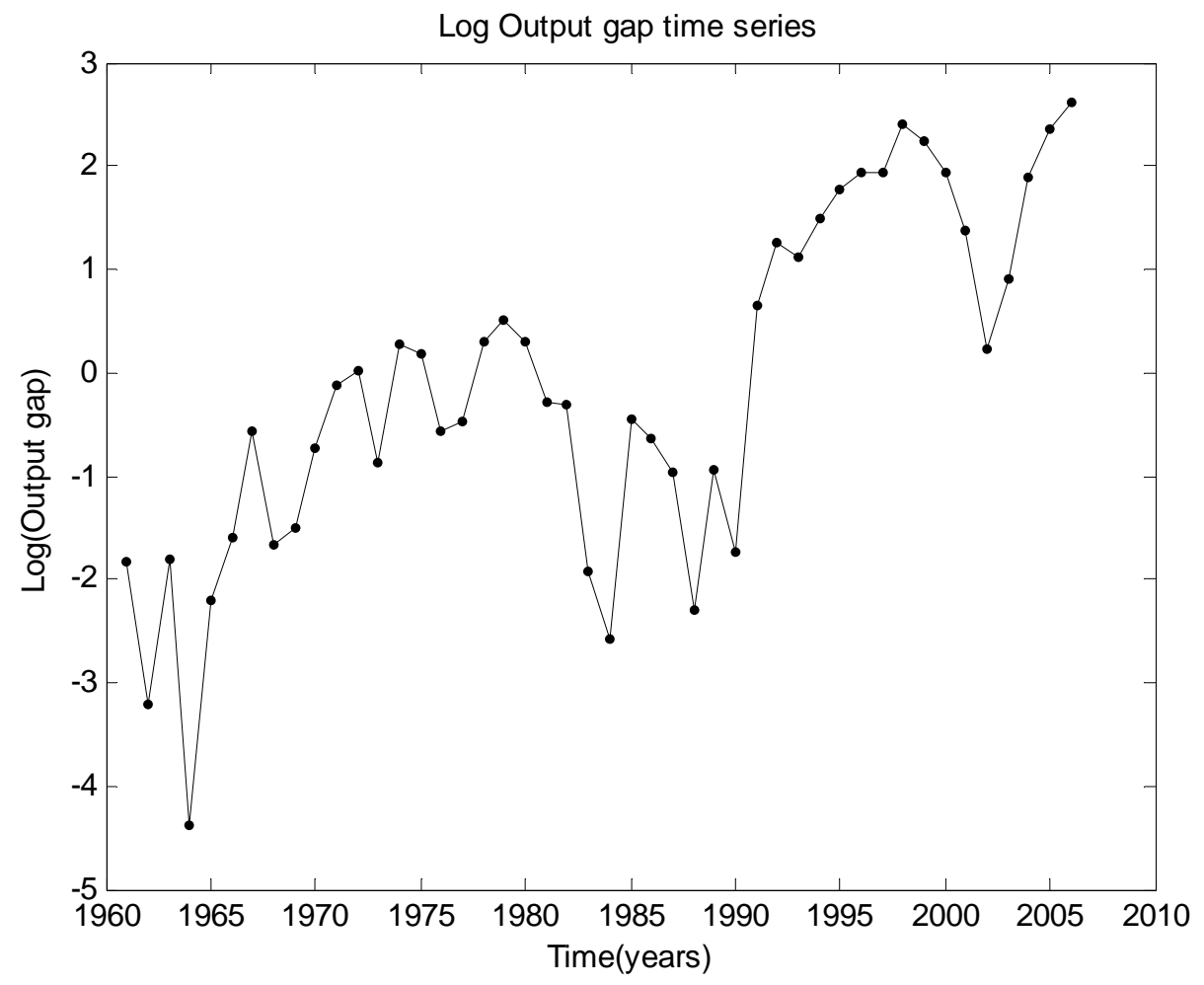

Figure 2 


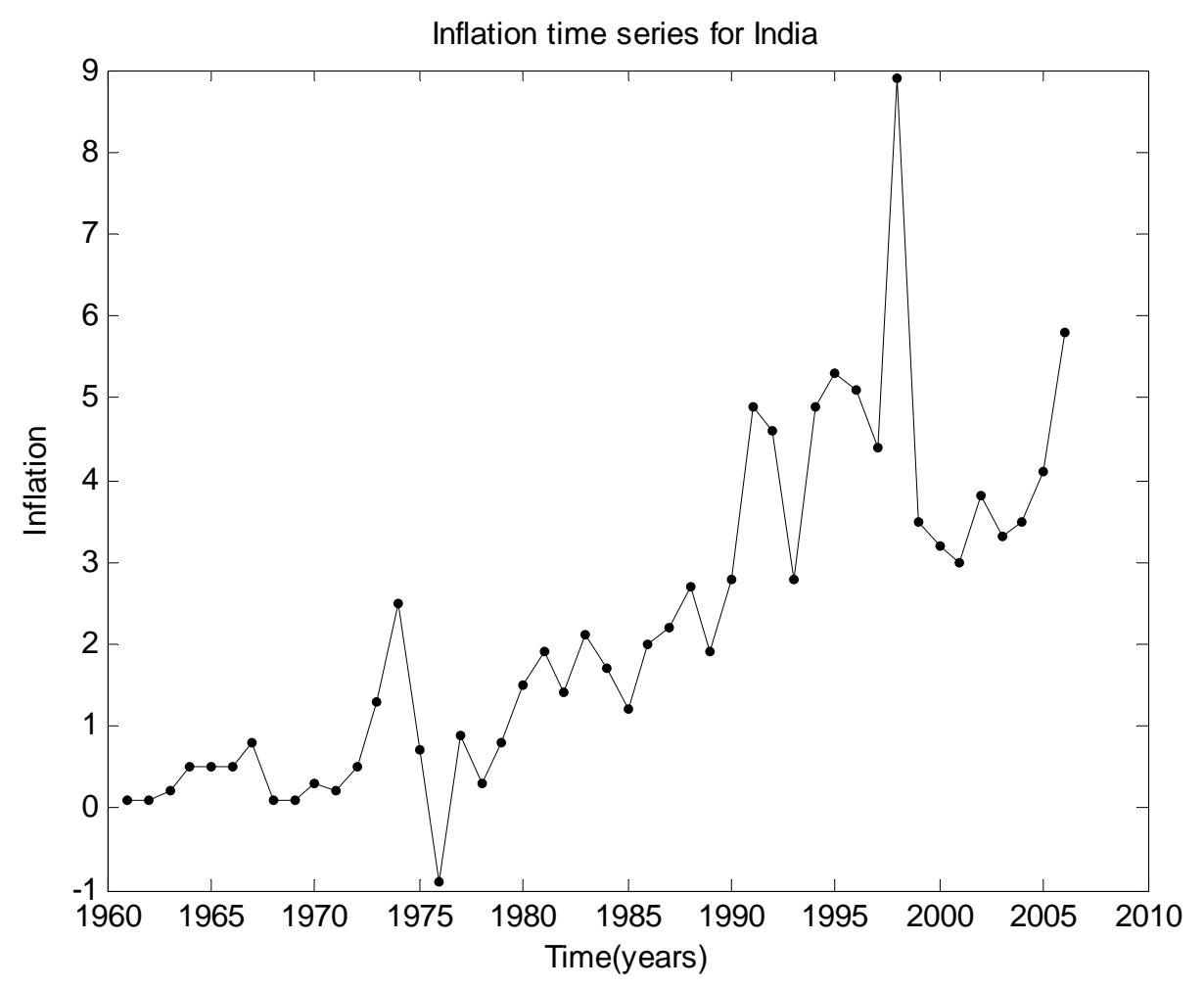

Figure 3

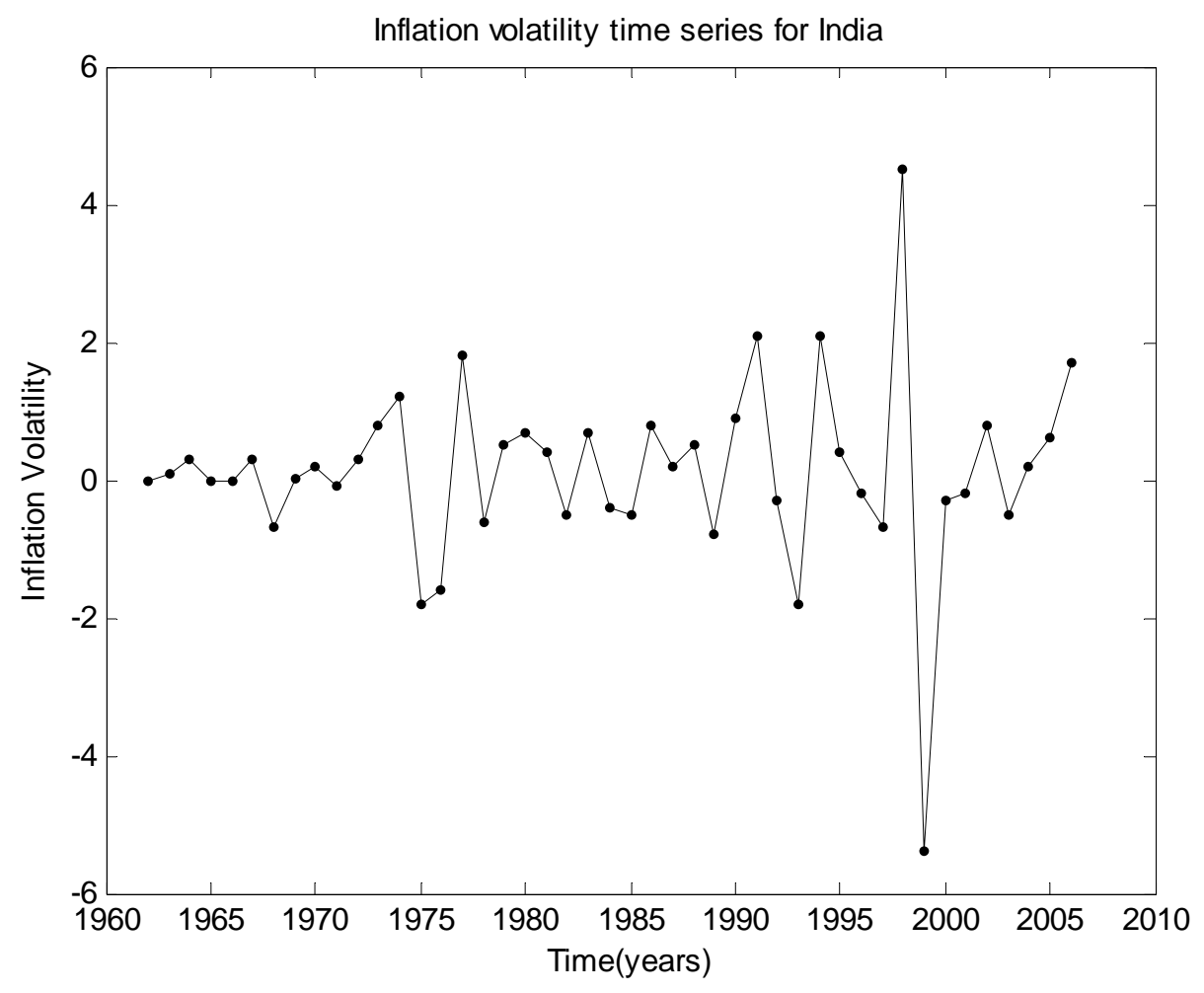

Figure 4 